\title{
Analysis of Urban Innovation Efficiency in Guangdong-Hong Kong-Macao Greater Bay Area
}

\author{
Shengqi Zhao \\ College of Economy, Jinan University, Guangzhou, China \\ Email: 304512372@qq.com
}

How to cite this paper: Zhao, S.Q. (2018) Analysis of Urban Innovation Efficiency in Guangdong-Hong Kong-Macao Greater Bay Area. Open Journal of Business and Management, 6, 539-550.

https://doi.org/10.4236/ojbm.2018.63040

Received: March 14, 2018

Accepted: May 8, 2018

Published: May 11, 2018

Copyright $\odot 2018$ by author and Scientific Research Publishing Inc. This work is licensed under the Creative Commons Attribution International License (CC BY 4.0).

http://creativecommons.org/licenses/by/4.0/

\begin{abstract}
Innovation is the country's core requirement for the construction of Guangdong-Hong Kong-Macao Greater Bay Area, and is also the core competitiveness of the Greater Bay Area. Due to the differences in the geographical, cultural, and institutional aspects of Guangdong, Hong Kong, and Macao, the complexity of regional innovation analysis has increased. This paper uses the DEA method to study the different efficiencies of each city in the Guangdong-Hong Kong-Macao Greater Bay Area, analyzes the input redundancy and output shortage of each city, and compares the scale efficiency and technical efficiency, policies and recommendations.
\end{abstract}

\section{Keywords}

Guangdong-Hong Kong-Macao Greater Bay Area, Innovation Efficiency, DEA

\section{Introduction}

\subsection{The Background of the Policy, Status Quo}

The proposal of Guangdong-Hong Kong-Macao Greater Bay Area has undergone a long process. The early days were mostly in the form of economic zones and port groups, such as the Greater Pearl River Economic Zone. Later, the proposed Hong Kong Bay Area was the earliest proposed Bay Area in China [1], Building ideas, it then goes to the concept of Lingdingyang Bay Area, Central Pearl River Estuary Bay Area. In the official document, the concept of the Bay Area officially emerged in 2005 as the "Pearl River Delta Urban Community Coordinated Development Plan". And for the first time in five years, the Na- 
tional Development [2] and Reform Commission and other ministries and commissions jointly released the "Vision and Action for Promoting the Joint Construction of the Silk Road Economic Belt and the 21st Century Maritime Silk Road". In the "Government Work Report" on the National "Two Conferences" in 2017, the reference to "Development of the Development Plan for the Guangdong-Hong Kong-Macao Greater Bay Area City Group" was formally proposed to the Guangdong-Hong Kong-Macao Greater Bay Area. The concept of a region has risen as a national strategy. Guangdong-Hong Kong-Macao Greater Bay Area mainly refers to Guangzhou, Shenzhen, Zhuhai, Dongguan, Zhaoqing, Shenzhen, Huizhou, Zhongshan, Jiangmen, and Hong Kong and Macau. The Guangdong-Hong Kong-Macao Greater Bay Area has three key elements for becoming a world-class Bay Area: the degree of participation in economic globalization, the openness of the internal economic structure, and the industrial revolution in science and technology.

On July 1, 2017, the National Development and Reform Commission, the Guangdong Provincial Government, the Government of the Hong Kong Special Administrative Region, and the Government of the Macao Special Administrative Region jointly signed the "Deepen Guangdong, Hong Kong and Macao Cooperation to Advance the Development of the Guangdong-Hong Kong-Macao Greater Bay Area," and in the framework agreement, targets, principles, and key areas of cooperation highlight the importance of innovation in the construction cooperation in the Greater Bay Area. Therefore, based on the current research and data available, this paper proposes targeted analysis and recommendations for the development of science and technology innovation in the Greater Bay Area.

\subsection{Comparison of Foreign Mature Development Models}

New York Bay, San Francisco Bay Area and Tokyo Bay Area are the most influential Three Bay Areas in the world today.

1) New York Bay Area

The New York Bay Area has a land area of 21,500 square kilometers, and the New York Bay Area consists of 25 counties. The main cities in the Bay Area are New York City, Newark and New Jersey. New York City is the center of the New York Bay Area and the largest city in the United States. Colleague New York Harbor is also the largest commercial port in the United States. At the same time, there are 58 universities including New York University and Columbia University in the Bay Area. The Bay Area of New York, as the only international bay area, is the core hub and commercial center of world finance. The Midtown Manhattan of New York City is the largest CBD gathering area in the world. At the same time, more than 100 well-known banks and insurance company headquarters have been gathered. The proportion of the tertiary industry in the entire Bay Area exceeds 90\%. The main industries in the New York Bay Area are real estate, finance and insurance, patent and technology services, healthcare, whole- 
sale and retail. In terms of educational attainment, the ratio of undergraduate education and above in the Bay Area of New York City accounted for $42 \%$. The New York Regional Planning Association played an important role in the development of planning in the New York Bay Area. The association is a purely non-governmental organization. The agency issued the "Regional Plan for New York and its Surrounding Areas" in 1929. This plan is also the first comprehensive plan for a metropolitan area in the world. Management, community systems [3] have had more than seven decades of influence. In the subsequent process, the association published a total of four regional development plans that have had an important impact on the New York Bay area.

2) San Francisco Bay Area

The San Francisco Bay Area has a land area of 18,000 square kilometers, including 101 cities in 9 counties and a total population of more than 7 million. The most famous cities in the Bay Area include San Francisco, Oakland City and San Jose. San Francisco is the core city of the Bay Area. San Jose is known as Silicon Valley. Although the population in the region is less than $1 \%$ of the United States, the GDP created accounts for 5\% of the United States. The entire bay is divided into five regions, North Bay, San Francisco City, East Bay, Peninsula and South Bay. Supported by this sparkling highlight of Silicon Valley, the San Francisco Bay Area not only hosts as many as 30 private venture capital funds, but more than $40 \%$ of the venture capital in the United States is concentrated here. The capital winds are turbulent and the technology and industry are expanding. Ultimately, it spawned world-famous companies such as Google, Apple, Facebook, and Intel.

3) Tokyo Bay Area

With a land area of 13,556 square kilometers, it is composed of the three metropolitan counties of Tokyo, Kanagawa Prefecture, Chiba Prefecture, and Saitama Prefecture. It has a population of 35 million people and accounts for $26.3 \%$ of Japan's total population. With Tokyo as the center, the Tokyo Bay area encompasses four major cities including Yokohama, Kawasaki, Funabashi, and Chiba. At the same time, Tokyo Bay is formed by Yokohama Port, Tokyo Port, Chiba Port, Kawasaki Port, Kisarazu Port, and Yokosuka. The horseshoe-shaped port groups connected to the six ports of Hong Kong have an annual throughput of more than 500 million tons. The huge group of ports has brought about industrial concentration and population concentration in the Tokyo Bay area. It also forged Japan's largest industrial city group and the largest international financial center, transportation center, business center, and consumer center.

4) Summary of the advantages of the world's three largest bays:

a) The superior geographical configuration, Bay Area land exchange on three sides, embracing the bay, so it has a superior ecological and location than the general coastal areas, which is suitable for the construction of different sizes of ports, forming a group of ports. Because of its close proximity to the sea, it encompasses a large area of water and thus has a natural environment and an excellent ecological environment. 
b) Developed port cities. The Bay Area has a long coastline and a wide range of ports. It can breed a number of port cities. The construction of the Bay Area Passage will make the Bay Area port city have the shortest commuting distance between the two points, and thus the economic link of the entire Bay Area will be closer. The port cities are also playing an important role in opening up to the outside world, attracting foreign investment, introducing advanced foreign technologies and production methods, and are an important connecting point.

c) Strong core city. The Bay Area economy is generally a multi-nuclear metropolitan area, and one city is a core city. The core cities are generally political and economic centers that have a certain influence in the region and the world. Other cities will seek development around the core cities.

d) A sound innovation system, the international large bay area often has a highly developed and complete industrial system. In the Sanwanwan area, there are not only institutions of higher learning that train high-end talent, but also large-scale research and development centers, as well as various types of innovative institutions, as well as this very important capital incubator. In order to promote the interaction between industry, universities and research institutes, the government will also various industrial cooperation platforms have been set up, so the Bay Area can produce a strong industrial cluster effect and high innovation efficiency.

e) Efficient transportation. Logistics, talent, technology flow, and capital flow among the various entities in the Bay Area will be deployed and delivered within the shortest possible time. As a result, the operating efficiency of the company and the work efficiency of its personnel have greatly improved. The efficiency of the urban network in the Bay Area has been fully demonstrated.

f) Sensitive division of labor and cooperation, the Bay Area economy generally involves multiple administrative regions. Whether it is the long-term division of labor and cooperation, the convergence of urban infrastructure, or the protection of the ecological environment, all need regional coordination, and the well-developed Bay Area economy is all reasonable. The division of labor and cooperation system includes strengthening the overall planning, clarifying the role of the city and the port, establishing the Bay Area Government Association, the Transportation Committee, and other governance organizations.

\subsection{The Status Quo of Innovation in Guangdong-Hong Kong-Macao Greater Bay Area and Its Current Shortcomings}

Guangdong-Hong Kong-Macao Greater Bay Area can be considered the fourth pole of the global economy, compared to the other three major Bay Areas. The Tai Wan District belongs to the Emerging Bay Area economy and its economic growth rate is relatively fast, but its economic strength is still weak. At the same time, although the financial and related industries in the Greater Bay Area need 
to be upgraded, the growth rate is relatively high. The gap between Guangdong-Hong Kong-Macao Greater Bay Area and the other three major bays is far behind in determining the development of the Bay Area, an important factor in the development of innovative technologies. According to the 2017 Forbes Innovation 100 ranking, Guangdong-Hong Kong-Macao Greater Bay Area has only one company on the list. At the same time, the output of high-tech products, patented inventions, and supporting systems for production, education, and research are still far from each other. In recent years, our country has continuously emphasized that we must replace China's manufacturing with China's creation, and innovation-driven has been an important strategy and direction for national development. Guangdong-Hong Kong-Macao Greater Bay Area is a key development area of the Bay Area. Innovation and technology are also important forces that drive the development of the Greater Bay Area into a world-class Bay Area. The status quo of the development of science and technology in Guangdong, Hong Kong and Macao is not the same:

1) Guangdong

In 2016, the total GDP of Guangdong was 795,205 million yuan, of which the GDP of the nine municipalities of the Guangdong-Hong Kong-Macao Greater Bay Area was 6830.59 billion yuan, accounting for the vast majority of the ratio. Guangdong's R \& D expenditure in 2015 was 179.82 billion yuan, accounting for $2.5 \%$ of GDP. The manufacturing scale of the nine cities in the Guangdong-Hong Kong-Macao Greater Bay Area ranks first in the country, and the system is complete. High-tech companies are highly concentrated and new technologies, new formats, and new models are rapidly growing. Guangdong Province has made outstanding achievements in the development of science and technology, gradually established regional innovation mechanisms and environment, and its innovation capability ranks among the top in the country.

The technological innovation environment is the basic condition for the survival and development of science and technology innovation. Since the 18th National Party Congress, the Guangdong Provincial Government has successively formulated a series of policies and systems to constantly optimize the policy environment for the development of technological innovation. In terms of innovative infrastructure, significant progress has been made in the construction of transportation, communications, and laboratory systems in Guangdong in recent years. By the end of 2014, Guangdong had formed a complete echelon laboratory system consisting of national plus-key laboratories. The competition for scientific and technological innovation is largely a competition for innovative talents. The quality of innovative talents directly determines the effectiveness of their participation in innovation activities. According to the plan, Guangdong will achieve $50 \%$ of the gross enrollment rate of higher education in 2020. As for the investment in technological innovation, R \& D [4] personnel of enterprises have always been the main part of R \& D personnel in Guangdong, and their innovation and vitality are strong. In 2014, the number of R \& D personnel in Guangdong exceeded 650,000 , which was three times that of 2007. At the same 
time, Guangdong's ability to attract academicians of the two academies and returned overseas students is also increasing year by year. From 2010 to 2014, the scale of R \& D expenditures in Guangdong has been expanding year by year, with a growth rate of over $16 \%$ from the previous quarter, and even $30 \%$ once. It can be seen that the environment for the development of science and technology in Guangdong is very good.

2) Hong Kong

According to the Global Competitiveness Report, Hong Kong is China's first competitive city, relying mainly on strong trading capabilities and improving its financial system. The Hong Kong economy has so far seen a total of four transitions. The fourth was the adjustment that began in the mid-to-late 1990s. From the economic growth, it mainly relied on the financial industry and the real estate industry to begin to pay close attention to the high-tech industry, and established a relationship with the Mainland. Better contact. The signing of CEPA in 2003 has brought new opportunities to the development of Hong Kong's industries. It has featured information technology Hong Kong's technology industry has begun to significantly increase its position in the Hong Kong industrial system. Hong Kong has a unique advantage over the Mainland. First, Hong Kong has talent, international technology and equipment resources, national network advantages, Hong Kong has a transparent and legal environment, and Hong Kong is a region with a relatively low tax rate in Asia. These are all attractive talents in Hong Kong. The convergence of a large number of international talents has saved Hong Kong's intellectual base for innovative research and development. This has made Hong Kong an incomparable advantage in terms of innovative $\mathrm{R} \& \mathrm{D}$ potential and strength. Hong Kong has received less international restrictions when introducing international advanced technology and equipment. Therefore, Hong Kong is more convenient than the Mainland in terms of scientific and technological information and personnel exchanges, research and development resources, and international contact networks.

3) Macau

The "2016-2020 Five-Year Plan" of Macao focuses on the eight major development strategies and deployments and incorporates four major development concepts: innovation, development, balanced development, joint development, and shared development. According to the statistics of the Macao government, the proportion of Macao's tertiary industry has increased from $88.3 \%$ in 2005 to $96.3 \%$ in 2013 and it has decreased to $94.9 \%$ in 2014 and $92.2 \%$ in 2015 . Among them, the highest single accounted for gaming industry, accounting for $48.0 \%$, while the higher growth in the secondary industry was in the construction industry, the higher increase in the tertiary industry was in insurance and retirement funds, and the reduction in more industries was gambling, Food, retail, and rental industries. Macau's economy is dominated by gambling, tourism, and trade [5], and is therefore heavily influenced by the external environment. In recent years, the cooperation between Guangdong and Macao has been conti- 
nuously strengthened. The signing of the "Guangdong-Australia Cooperation Framework Agreement" and the establishment of the Hengqin Economic Development Zone are all efforts to create a new economic region in the world.

\section{The Empirical Analysis of DEA Efficiency}

\subsection{Model Introduction}

The DEA was born in 1978 and was first proposed by the famous transporters Charnes, Cooper and Rhode. The DEA method introduced by domestic academic circles was introduced by Wei Quanling in 1988. The efficiency measure is divided into parameter method and non-parameter method. The more commonly used parameter method is SFA. Although this method can reduce the sensitivity of production frontiers to random errors, it still has essential deficiencies. For example, if the production frontier function form is assumed in advance, the measurement results will be subject to the specific form of the model. Impact and so on. Non-parametric methods are the most classic of data envelopment analysis (DEA). Researchers only need to focus on those variables that they care about without having to worry about whether the selected variables best reflect the output efficiency. In this case [6], although no researcher can guarantee that all relevant variables are included in the input and output, this does not mean that the research will be biased, as long as the selected variable can serve the researched issue. It is precisely because the DEA method does not need to preset the form of the production function in advance and does not need to describe the production process. The evaluation index has advantages such as comprehensiveness and comparability, which is used by many scholars in the empirical study. This paper also chooses this method to measure.

\subsection{Data Reference and Description}

The research object of this paper is Guangdong-Hong Kong-Macao Greater Bay Area, and the current researches are mainly directed at the policy suggestions for Guangdong, Hong Kong, and Macao innovation. This article intends to conduct further detailed discussions on innovation in the Greater Bay Area. The statistical data on innovation in the nine cities of Guangdong and Hong Kong are all relatively good. The main industries in Macau are the tourism and gaming industries. There is no complete statistical data on Macao's innovation and technology, and data cannot be obtained. Therefore, the data used in the empirical research mainly used in this paper are nine cities in Guangdong and Hong Kong.

\subsection{Empirical Analysis}

According to Table 1, there are seven cities where DEA is ineffective, among which there are Guangzhou, Shenzhen, Foshan, Dongguan and Hong Kong. There are Zhuhai and Jiangmen with insufficient resources. The DEA in Zhaoqing, Huizhou and Zhongshan are effective. The result of the improvement based on the DEA results is: 
Table 1. City innovation data.

\begin{tabular}{ccccc}
\hline & \multicolumn{2}{c}{ Technological innovation output } & \multicolumn{2}{c}{ Technological innovation input } \\
\hline City & $\begin{array}{c}\text { Number of } \\
\text { patent } \\
\text { applications }\end{array}$ & $\begin{array}{c}\text { Above-scale enterprise } \\
\text { high-tech output } \\
\text { value (billion) }\end{array}$ & $\begin{array}{c}\text { Total social R \& D } \\
\text { investment (billion) }\end{array}$ & $\begin{array}{c}\text { R \& D staff } \\
\text { number }\end{array}$ \\
\hline Guangzhou & 46,312 & 8001.36 & 291.58 & 68,618 \\
Shenzhen & 82,254 & $15,560.07$ & 580.01 & 158,465 \\
Zhuhai & 8998 & 1047.11 & 40 & $12,775.7$ \\
Foshan & 29,707 & 2812.59 & 161.28 & 54,816 \\
Jiangmen & 8345 & 1050 & 31.8 & 11,542 \\
Zhaoqing & 1781 & 1055.27 & 14.95 & 9300 \\
Huizhou & 18,359 & 3600 & 59 & 9618 \\
Dongguan & 28,431 & 4742.72 & 109.93 & 50,112 \\
Zhongshan & 24,618 & 2600 & 67.7592 & 9757 \\
Hong Kong & 13,129 & 4524.7 & 121.98 & 26,045 \\
\hline
\end{tabular}

Data sources: statistical yearbooks by city in 2014 .

The ratio of the difference between the target size and the actual scale of innovation input and the actual scale is the input redundancy ratio of innovation, and the ratio of the difference between the target size and the actual size of innovation output and the actual scale is the ratio of the innovation output. According to the input redundance and output insufficiency rate of ten cities, it is clear which input and output indicators need to be improved and how to improve in the process of innovation and development, which will help to achieve regional innovation and funny development. According to the results of the effectiveness evaluation, the output shortage rate and the input redundancy rate in the Guangdong-Hong Kong-Macao Greater Bay Area can be calculated.

\subsection{Analysis of Results}

According to Table 2, Zhuhai's $\mathrm{R} \& \mathrm{D}$ investment redundancy rate is $0.209, \mathrm{R} \&$ $\mathrm{D}$ personnel redundancy is 0.261 , but Zhuhai has both a redundancy rate and an output shortage rate, and its high-tech output value needs to be improved by $47.33 \%$. Will, Zhuhai also belongs to the stage of increasing scale. Foshan's R \& $\mathrm{D}$ investment fund redundancy ratio is $0.299, \mathrm{R} \& \mathrm{D}$ personnel redundancy is $58.2 \%$, and the high-tech output rate is $33.1 \%$. Jiangmen's $\mathrm{R} \& \mathrm{D}$ investment funds have a redundancy rate of $0.053, \mathrm{R} \& \mathrm{D}$ personnel redundancy is 0.183 , and high-tech output is $42.7 \%$.

Hong Kong's R \& D investment funds have a redundancy rate of $0.186, \mathrm{R} \& \mathrm{D}$ personnel redundancy is 0.189 , and the number of patent applications is insufficient at $77.46 \%$. It can be seen that Hong Kong's ability to transform production, research, and research is relatively strong, so there is no shortage of high-tech output, and the number of patent applications represented by research and development needs to be strengthened. 
According to the analysis results in Table 3, it can be seen that Zhaoqing, Huizhou, and Zhongshan are DEA effective, that is, the optimal combination of inputs and outputs. However, Zhuhai, Foshan, Jiangmen, and Hong Kong all have different levels of input redundancy and output shortages. It shows that the input and output of Zhuhai, Foshan, and Jiangmen are irrational, and the pure technical efficiency is less than 1, especially in the transformation of scientific and technological achievements. The efficiency of resource input needs to be improved. Zhuhai and Jiangmen are in the stage of increasing scale, and are still in the ascending stage. They can increase input, adjust input ratio and efficiency, and increase output. While Guangzhou, Shenzhen, Foshan, Dongguan, and Hong Kong are all in the phase of diminishing economies of scale, they show

Table 2. Data processing results.

\begin{tabular}{|c|c|c|c|c|}
\hline \multirow[b]{2}{*}{ City } & \multicolumn{2}{|c|}{ Technological innovation output } & \multicolumn{2}{|c|}{ Technological innovation input } \\
\hline & $\begin{array}{l}\text { Number of } \\
\text { patent } \\
\text { applications }\end{array}$ & $\begin{array}{c}\text { Above-scale } \\
\text { enterprise high-tech } \\
\text { output value (billion) }\end{array}$ & $\begin{array}{l}\text { Total social R \& D } \\
\text { investment } \\
\text { (billion) }\end{array}$ & $\begin{array}{c}\text { R \& D staff } \\
\text { number }\end{array}$ \\
\hline Guangzhou & 46,312 & 8001.36 & 291.58 & 68,618 \\
\hline Shenzhen & 82,254 & $15,560.07$ & 580.01 & 158,465 \\
\hline Zhuhai & 8998 & 1543.439 & 31.64 & 9444.422 \\
\hline Foshan & 29,707 & 3744.316 & 112.99 & 22887.25 \\
\hline Jiangmen & 8345 & 1499.269 & 30.129 & 9431.355 \\
\hline Zhaoqing & 1781 & 1055.27 & 14.95 & 9300 \\
\hline Huizhou & 18,359 & 3600 & 59 & 9618 \\
\hline Dongguan & 28,431 & 4742.72 & 109.93 & 50,112 \\
\hline Zhongshan & 24618 & 2600 & 67.7592 & 9757 \\
\hline Hong Kong & 23299.05 & 4524.7 & 99.282 & 21126.13 \\
\hline
\end{tabular}

Table 3. DEA analysis of data using DEAP software.

\begin{tabular}{ccccc}
\hline & CRSTE & VRSTE & SCALE & \\
\hline Guangzhou & 0.492 & 1 & 0.492 & drs \\
Shenzhen & 0.451 & 1 & 0.451 & drs \\
Zhuhai & 0.631 & 0.791 & 0.798 & irs \\
Foshan & 0.507 & 0.701 & 0.724 & drs \\
Jiangmen & 0.749 & 0.947 & 0.791 & irs \\
Zhaoqing & 1 & 1 & 1 & - \\
Huizhou & 1 & 1 & 1 & - \\
Dongguan & 0.793 & 1 & 0.793 & drs \\
Zhongshan & 1 & 1 & 1 & drs \\
Hong Kong & 0.598 & 0.814 & 0.734 & \\
\hline
\end{tabular}


that the increase rate of output is smaller than the input ratio of production factors. The efficiency gains of these cities do not lie in the continuous increase of investment, but in how Increase output capacity and resource utilization capacity. The relatively pure technical efficiency and scale efficiency are available, as are Jiangmen, Guangzhou, Shenzhen, Dongguan, and Hong Kong. The scale efficiency is the overall efficiency.

\section{Policy Suggestions}

Regional economic development is often unbalanced. Regional conditions, resource endowments, and human factors determine the economic gradient of a region. The level of economic gradient determines, to some extent, its ability to innovate and the level of innovation and radiation capabilities. The DEA model for the efficiency of input and output in the current Guangdong-Hong Kong-Macao Greater Bay Area in the previous section reflects that the innovation efficiency varies from city to city. These differences are determined not only by the innovation factors themselves, but also by the economy of the cities in the region. Development, geographical and cultural conditions are all related. Therefore, this paper combines the above issues and status quo and proposes the following suggestions:

\subsection{Establish and Improve the Administrative and Legal Systems in the Three Places}

Under the National Belt and Road Initiative and innovation-driven strategy, the state has paid more and more attention to the development of the Greater Bay Area in recent years, and has promoted Guangdong-Hong Kong-Macao Greater Bay Area to a national strategy. Guangdong-Hong Kong-Macao Greater Bay Area [7] has three customs areas, three currencies, and the area has three major free trade areas [8]: Guangzhou Nansha, Shenzhen Qianhai, and Zhuhai Hengqin. Although the regional economic system and political system are more complex than those in the foreign Bay Area, the construction of the three major free trade areas has strengthened the economic ties between the three places and has contributed to economic integration. In recent years, the forums and policies concerning collaborative innovation in the Guangdong-Hong Kong-Macao Greater Bay Area have been continuously held and introduced. The government is also making continuous efforts for collaborative innovation in the three places. However, to effectively improve the efficiency of innovation cooperation between the three places, it is necessary under the "One Country, Two Systems" and CEPA Agreement, it is proposed that local governments should take the guidance of the local government and coordinate the participation in the administrative management system. It is proposed to establish a permanent office for innovation and coordination offices in the Greater Bay Area of Guangdong Province, to improve the joint meeting mechanism for the chief executives of Guangdong, Hong Kong and Guangdong, and to increase the practical effec- 
tiveness of the joint conferences in promoting scientific and technological cooperation and innovation and establish a direct communication and coordination mechanism.

\subsection{Ability to Cooperate with Regional Scientific Research Achievements}

The R \& D personnel and capital input of the three places are different. Hong Kong's R \& D personnel account for nearly half of the input of middle and higher education institutes and institutions, while Guangdong's R \& D personnel and input to middle schools and institutions account for only about $10 \%$. For the actual productivity, it should strengthen innovation and technology exchange among universities and institutions in the region, increase investment in education and scientific research in universities and research institutes in the Bay Area, build world-class universities and scientific research institutions, and lay out national major scientific research projects to boost scientific research achievements.

\subsection{Give Full Play to the Advantages of Cities, Strengthen Resource Integration and Cooperation}

Through the above analysis, we can see that the innovation efficiency of each city in the region is different, and each city can complement each other to improve efficiency. The Greater Bay Area wants to create a strong and innovative Bay Area. Apart from Kechuang's ability, the financial environment is of utmost importance. The reason why Silicon Valley can become an innovation center has a lot to do with San Francisco's venture capital mechanism. The New York Bay area is better developed and is also related to Wall Street. Guangdong-Hong Kong-Macao Greater Bay Area also has such an advantage. As a global financial center, Hong Kong has the international experience of financial development. In 2016, the total amount of funds raised by newly listed companies in Hong Kong has been ranked first in the world, indicating that the influence of Hong Kong's capital markets may exceed that of New York in the future. Therefore, Guangdong-Hong Kong-Macao Greater Bay Area can learn from the "Silicon Valley" experience of the "innovation technology + ecological fund dual-core headquarters" in San Francisco Bay Area [9] and give full play to the functional role of important financial centers in the Bay Area, attracting more venture capital funds from around the world. Intermediary agencies and start-up companies have entered the Bay Area to build a "science and technology + financial" ecosystem.

\section{References}

[1] Jankowska, B., Matysek-Jędrych, A. and Mroczek-Dąbrowska, K. (2017) Efficiency of National Innovation Systems Poland and Bulgaria in the Context of the Global Innovation Index. Comparative Economic Research, 20, 77-94.

https://doi.org/10.1515/cer-2017-0021 
[2] Deng, Z.X. (2014) Construction of Shenzhen Free Trade Zone under the Economic Development Strategy of the Bay Area. Special Economic Zone, No. 12, 15-17.

[3] Schumpeter, J. (2000) Economic Development Theory. Beijing Commercial Press, Beijing.

[4] Buzard, K., Carlino, G.A., Hunt, R.M., Carr, J.K. and Smith, T.E. (2017) The Agglomeration of American R \& D Labs. Journal of Urban Economics, 101, 14-26. https://doi.org/10.1016/j.jue.2017.05.007

[5] Li, Y., Zheng, S.L. and Liang, Y.C. (2017) The Integration Development of Guangdong, Hong Kong, and Macao in the Greater Bay Area under Trade Promotion. Tropical Geography, 37, 792-801.

[6] Wu, Z.C. (2017) Taking Advantage of the Development of Guangzhou-Hong Kong-Macao Bay Area to Accelerate Innovation-Driven Development in Guangzhou. Special Economic Zone, No. 9, 14-17.

[7] Ding, X.G. (2017) Drawing on the Innovative Experience of the San Francisco Bay Area, the Guangdong-Hong Kong-Macao Bay Area Innovation Community Was Constructed. Exploration, No. 6, 27-30.

[8] Zhong, Y. and Hu, X.H. (2017) The Construction and System Innovation of Guangdong, Hong Kong, and Macao Bay Area: Theoretical Basis and Implementation Mechanism. Economist, No. 12, 50-57.

[9] Wang, H.B. (2014) Bay Area Economy and China Practice. China Economic Report, No. $11,99-100$. 